\title{
Development and Characterization of Microsatellite Markers in The Small Indian Mongoose (Urva Auropunctata)
}

\section{Takuma Sato}

Okinawa University

Takamichi Jogahara ( $\nabla$ t-jogahara@okinawa-u.ac.jp)

Okinawa University https://orcid.org/0000-0002-7388-6856

\section{Short Report}

Keywords: Genome wide screening, Introduced species, Okinawa, Population genetics, SSR

Posted Date: June 4th, 2021

DOl: https://doi.org/10.21203/rs.3.rs-535262/v1

License: (c) (1) This work is licensed under a Creative Commons Attribution 4.0 International License.

Read Full License 


\section{Abstract}

The small Indian mongoose (Urva auropunctata) is listed among 100 of the World's Worst Invasive Alien Species and eradication programs are ongoing worldwide. The development of individual and sex identification markers will improve their management. Therefore, we searched for novel mongoose short simple repeat (SSR) markers using genome-wide screening and identified 115,265 tetra-nucleotide repeat loci. Of 96 loci tested, 17 were genotyped in 28 mongooses from the Okinawa population. The genetic diversity analysis showed that the average expected and observed heterozygosity and number of alleles were $0.55,0.56$, and 2.94, respectively. Of 17 loci, one deviated from Hardy-Weinberg equilibrium and six loci pairs were likely linked to each other. However, we succeed in identifying all individuals using all of the SSR loci. The novel sex identification markers worked successfully in a test using six known sex samples. These novel SSR and sex identification markers should be useful in studies of individual identification and population genetics of the mongoose.

\section{Introduction}

The small Indian mongoose Urva auropunctata (Hodgson, 1836) is a generalist predator that naturally occurs from the Arabian Peninsula to Southeast Asia [1]. It was introduced to 64 islands in the Pacific and Indian Oceans and Caribbean and Adriatic Seas and to mainland Europe, South America, Australia, and North America for rat or snake control, causing enormous damage to the native biodiversity [2]. Now, this species is listed among 100 of the World's Worst Invasive Alien Species [3]. Ecological niche modelling of the mongoose suggests that it will spread globally by 2050 [4].

Mongoose eradication programs are underway using trapping and poisoning. On Amami Oshima Island, Japan, the program is close to success [5], and the populations and distributions of the endemic Amami rabbit Pentalagus furnessi (Stone, 1900) and Amami spiny rat Tokudaia osimensis (Abe, 1933) have expanded $[6,7]$. To continue these eradication programs, methods to estimate the mongoose population and density are needed.

The application of genetic analysis is essential for wildlife management [8]. Simple short repeat (SSR) markers are often used for individual identification and population size estimation using DNA collected from non-invasive samples, such as faeces or hair, because non-invasive sampling is easier than invasive sampling. Moreover, SSR analysis shows the genetic diversity of the target species.

Previously, eight mongoose SSR markers (dinucleotide repeats) were developed [9]; however, there are problems with their use. Three of these loci could not be amplified, implying that the annealing temperatures of the loci were unstable [10]. This problem leads to mis-genotyping and reduces the power of individual identification.

This study developed novel SSR markers for the small Indian mongoose using genome-wide screening in a mongoose from the Okinawa, Japan, population. We selected tetra-nucleotide repeats with short amplification lengths as markers so that they could be used for degraded DNA samples, such as faeces. 
We also developed sex identification markers. The novel markers were verified with 28 mongooses from the Okinawa population.

\section{Materials And Methods}

\section{Genome sequences and identification of microsatellite loci}

Genomic DNA was extracted from a small Indian mongoose tissue sample (Nago1; Table 1) and the genome was sequenced by Macrogen Japan (Kyoto, Japan). Whole-genome shotgun sequencing was performed on an Illumina NovaSeq 6000 sequencer (150 paired ends). The sequence quality was checked by FastQC [11] and noise and adapters were trimmed with fastp [12] under the default configurations. We then mapped the sequences onto the genome of a banded mongoose Mungos mungo (acc. no. GCA_004023785) using BWA-mem2 [13] with the default parameters. Among the species with genome information, $M$. mungo is most closely related to the small Indian mongoose [14]. To produce the consensus sequence, the output BAM file was sorted using SAMtools [15] and the variants were called with bcftools. In total, 52,502 sequences were obtained, with a total valid sequence length of $1,435,707,730 \mathrm{bp}$.

The microsatellite loci were identified from the consensus sequences using Krait [16] with the following configuration: perfect SSRs search mode; minimum repeat number of tetra-nucleotide SSRs = 7; and flanking sequence length $=200$. We selected tetra-nucleotide SSRs because the repeats are easy to determine and the genotype is less prone to slippage [17]. To search for primers, Primer3 [18] implemented in Krait was used with following configuration: primer product size range $=80-270$; primer GC content $=40-60$; and Primer Max Ns accepted as 0 . The other parameters were set to the default values. In total, 115,265 tetra-nucleotide repeat loci were found and 10,224 primer pairs were exposed. Of these, 96 primer pairs were selected for multiplex PCR amplification based on their product sizes, which were around 80, 120, 160, or $200 \mathrm{bp}$. To avoid linkage disequilibrium, a marker was selected from each scaffold.

\section{Genotyping microsatellite loci}

To verify the novel SSR markers, tissue samples from 28 mongooses in the Okinawa population obtained through the mongoose eradication program were used (Table 1). Total DNA was extracted with the DNeasy Blood \& Tissue Kit (QIAGEN, Hilden, Germany) according to the manufacturer's protocol. All PCRs were conducted with QIAGEN Multiplex PCR kits in a total volume of $10 \mu \mathrm{L}$, with $5 \mu \mathrm{L}$ Multiplex PCR

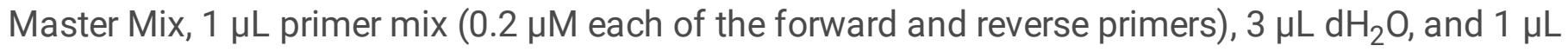
genomic DNA. The PCR amplification comprised $95^{\circ} \mathrm{C}$ for $15 \mathrm{~min} ; 35$ cycles at $94^{\circ} \mathrm{C}$ for $30 \mathrm{~s}, 60^{\circ} \mathrm{C}$ for 90 $\mathrm{s}$, and $72^{\circ} \mathrm{C}$ for $60 \mathrm{~s}$; then $60^{\circ} \mathrm{C}$ for 30 min on a MiniAmp Plus thermal cycler (Applied Biosystems [ABI], Foster City, CA, USA). The amplicons were checked by electrophoresis on $3 \%$ agarose gels. Based on Schuelke [19], we ordered universal primers with four different fluorescent dyes at the 5 ' ends (5'CACGACGTTGTAAAACGAC3' for 6-FAM, 5'TGTGGAATTGTGAGCGG3' for VIC, 5'CGGAGAGCCGAGAGGTG3' for NED, or 5'CTATAGGGCACGCGTGGT3' for PET), and new forward primers 
tagged with one of the four different universal primers at the 5 ' end for the successfully amplified loci. The primer mixes were prepared according to Culley et al. [20]. Fragment analysis was conducted by the FASMAC DNA sequencing service (FASMAC, http://fasmac.co.jp/) on an ABI 3130xl Genetic Analyzer with GeneScan 600 LIZ Size Standard (ABI). For genotyping, Peak Scanner 1.0 (ABI) was used, and we checked the repeatability of heterozygotes twice and homozygotes three times.

\section{Development of sex identification markers}

Based on the sequences of zinc finger protein genes on the $X(Z F X ; A B 848712)$ and $Y(Z F Y ; A B 848711)$ chromosomes from Murata et al. [21], new mongoose sex identification markers were designed (Table 2). The PCR product length was $174 \mathrm{bp}$ for $Z F X$ and $221 \mathrm{bp}$ for $Z F Y$. This sex identification process was confirmed by PCR amplification with six known sex samples via electrophoresis on a $3 \%$ agarose gel. We used the same PCR volumes as for SSR and the following PCR conditions: $95^{\circ} \mathrm{C}$ for $15 \mathrm{~min} ; 35$ cycles at $94^{\circ} \mathrm{C}$ for $30 \mathrm{~s}, 58^{\circ} \mathrm{C}$ for $90 \mathrm{~s}$, and $72^{\circ} \mathrm{C}$ for $30 \mathrm{~s}$; then $72^{\circ} \mathrm{C}$ for $10 \mathrm{~min}$.

\section{Molecular data analyses}

For all microsatellite loci, the observed $(\mathrm{Ho})$ and expected $(\mathrm{He})$ heterozygosity, deviation from HardyWeinberg equilibrium (HWE), inbreeding coefficient (Fis), and linkage disequilibrium were analysed using GENEPOP [22]. The presence of null and dropout alleles was tested with Micro-checker [23]. The probabilities of identity (PID and PIDsib) were calculated by GIMLET [24].

\section{Results And Discussion}

Of 96 loci tested, 18 produced single bands of the target size. All loci except one successfully scored the genotypes by fragment analysis, and two to five alleles were found in the Okinawa mongoose population (Table 2). The microsatellite loci sequences were deposited in the DNA Data Bank of Japan (acc. no. XXXX to XXXX). He, Ho, and Fis were $0.33-0.67,0.39-0.82$, and $-0.2756-0.1787$, respectively (Table 2). Micro-checker suggested that no loci showed evidence of null alleles, while one locus (Uau16) deviated from HWE expectations $(P<0.003)$. Based on linkage disequilibrium tests, six loci pairs were likely linked $(P<0.05)$ : Uau 1 and 17 , Uau1 and 7, Uau 1 and 8 , Uau3 and 7, Uau6 and 13 , and Uau7 and 10. Generally, the genetic diversity of invasive species is lower than in the native population owing to the small number of founders or bottlenecks. There were at most 17 founders of the Okinawa mongoose population [25]. This history suggests that the Okinawa population might not follow HWE expectations. Using all 17 loci, 28 individuals were identified genetically; the PID was $1.92 \times 10^{-10}$ and the PIDsib $3.68 \times 10^{-5}$ using all 17 loci. At minimum, four loci were required to reach PID $<0.001$ and seven loci were required to reach PIDsib $<0.01$. This suggests that our novel SSR markers are useful for individual identification.

Moreover, the novel sex identification markers successfully distinguished three males and three females (Fig. 1).

As a result, we successfully developed 17 SSR and sex identification markers. These markers should be powerful tools for managing mongooses. 


\section{Declarations}

Acknowledgements

We are grateful to Mr. Katsushi Nakata, Dr. Ryoji Fukuhara, Yambaru Mongoose Busters and Yambaru Wildlife Center of the Ministry of Environment, Japan for providing samples, and Dr. Gohta Kinoshita, Ms. Yu Endo and Mr. Shinta Gima for their technical advices and supports. Computations were partially performed on the NIG supercomputer at ROIS National Institute of Genetics.

\section{Conflict of interest}

All authors declare no conflicts of interest.

\section{Consent to participate}

All the authors listed have approved the manuscript that is enclosed.

\section{Consent for publication}

The manuscript is approved by all authors for publication.

\section{Funding}

This research was performed by the Environment Research and Technology Development Fund (JPMEERF20204006) of the Environmental Restoration and Conservation Agency of Japan.

\section{Contributions}

TS and TJ contributed to the research idea and manuscript writing. TS contributed to experimental design and data analysis.

\section{References}

1. Gilchrist JS, Jennings AP, Veron G, Cavallini P (2009) Family Herpestidae (Mongooses). In: Wilson DE, Mittermeier RA (eds) Handbook of the Mammals of the World: Vol. 1, Carnivores. pp. 222-329

2. Barun A, Hanson C (2011) A review of small Indian mongoose management and eradications on islands. In: Veitch CR, Clout MN, Towns DR (eds) Island Invasives: Eradication and Management. Gland, pp. 17-25

3. Lowe, S., Browne, M., Boudjelas, S., De Poorter M (2000) 100 of The World's Worst Invasive Alien Species: A Selection from The Global Invasive Species Database. Invasive Species Specialist Group (ISSG), a specialist group of the Species Survival Commission (SSC) of the World Conservation Union (IUCN), 12 pp

4. Louppe V, Leroy B, Herrel A, Veron G (2020) The globally invasive small Indian mongoose Urva auropunctata is likely to spread with climate change. Sci Rep 10:1-11. 
https://doi.org/10.1038/s41598-020-64502-6

5. Watari Y (2019) Roadmap and checklist of invasive species management: Learning from the mongoose eradication project on Amami-Oshima. Japanese J Ornithol 68:263-272. https://doi.org/10.3838/jjo.68.263

6. Watari Y, Nishijima S, Fukasawa M, et al. (2013) Evaluating the "recovery level" of endangered species without prior information before alien invasion. Ecol Evol 3:4711-4721. https://doi.org/10.1002/ece3.863

7. Fukasawa K, Miyashita T, Hashimoto T, et al. (2013) Differential population responses of native and alien rodents to an invasive predator, habitat alteration and plant masting. Proc R Soc B Biol Sci 280. https://doi.org/10.1098/rspb.2013.2075

8. Browett SS, O'Meara DB, McDevitt AD (2020) Genetic tools in the management of invasive mammals: recent trends and future perspectives. Mamm Rev 50:200-210. https://doi.org/10.1111/mam.12189

9. Thulin C-G, Gyllenstrand N, Mccracken G, Simberloff D (2002) Highly variable microsatellite loci for studies of introduced populations of the small Indian mongoose (Herpestes javanicus). Mol Ecol Notes 2:453-455. https://doi.org/10.1046/j.1471-8278 .2002.00275.x

10. Barun A, Niemiller ML, Fitzpatrick BM, et al. (2013) Can genetic data confirm or refute historical records? The island invasion of the small Indian mongoose (Herpestes auropunctatus). Biol Invasions 15:2243-2251. https://doi.org/10.1007/s10530-013-0447-6

11. Andrews S (2014) FastQC: a quality control tool for high through put sequence data. https://www.bioinformatics.babraham.ac.uk/projects/fastqc/

12. Chen S, Zhou Y, Chen Y, Gu J (2018) Fastp: An ultra-fast all-in-one FASTQ preprocessor. In: Bioinformatics. Oxford University Press, pp i884-i890

13. Vasimuddin Md, Misra S, Li H, Aluru S (2019) Efficient architecture-aware acceleration of BWA-MEM for multicore systems. In: Proceedings - 2019 IEEE $33^{\text {rd }}$ International Parallel and Distributed Processing Symposium, IPDPS 2019. Institute of Electrical and Electronics Engineers Inc., pp 314324

14. Patou ML, Mclenachan PA, Morley CG, et al. (2009) Molecular phylogeny of the Herpestidae (Mammalia, Carnivora) with a special emphasis on the Asian Herpestes. Mol Phylogenet Evol 53:6980. https://doi.org/10.1016/j.ympev.2009.05.038

15. Li H, Handsaker B, Wysoker A, et al. (2009) The sequence alignment/map format and SAMtools. Bioinformatics 25:2078-2079. https://doi.org/10.1093/bioinformatics/btp352

16. Du L, Zhang C, Liu Q, et al. (2018) Krait: An ultrafast tool for genome-wide survey of microsatellites and primer design. Bioinformatics 34:681-683. https://doi.org/10.1093/bioinformatics/btx665

17. Guichoux E, Lagache L, Wagner S, et al. (2011) Current trends in microsatellite genotyping. Mol Ecol Resour 11:591-611. https://doi.org/10.1111/j.1755-0998.2011.03014.x 
18. Untergasser A, Cutcutache I, Koressaar T, et al. (2012) Primer3-new capabilities and interfaces. Nucleic Acids Res 40:e115-e115. https://doi.org/10.1093/nar/gks596

19. Schuelke M (2000) An economic method for the fluorescent labeling of PCR fragments. Nat Biotechnol 18:233-234. https://doi.org/10.1038/72708

20. Culley TM, Stamper TI, Stokes RL, et al. (2013) An efficient technique for primer development and application that integrates fluorescent labeling and multiplex PCR. Appl Plant Sci 1:1300027. https://doi.org/10.3732/apps.1300027

21. Murata C, Sawaya H, Nakata K, et al. (2016) The cryptic Y-autosome translocation in the small Indian mongoose, Herpestes auropunctatus, revealed by molecular cytogenetic approaches. Chromosoma 125:807-815. https://doi.org/10.1007/s00412-015-0572-3

22. Raymond M, Rousset F (1995) GENEPOP (Version 1.2): Population genetics software for exact tests and ecumenicism. J Hered 86:248-249. https://doi.org/10.1093/oxfordjournals.jhered.a111573

23. Van Oosterhout C, Hutchinson WF, Wills DPM, Shipley P (2004) MICRO-CHECKER: Software for identifying and correcting genotyping errors in microsatellite data. Mol Ecol Notes 4:535-538. https://doi.org/10.1111/j.1471-8286.2004.00684.x

24. Valière N (2002) GIMLET: a computer program for analysing genetic individual identification data. Mol Ecol Notes 2:377-379. https://doi.org/10.1046/j.1471-8286.2002.00228.x-i2

25. Kosei I (1966) Distribution and eating habits of mongoose in Okinawa. Okinawa Agric 5:39-44.

\section{Tables}

Due to technical limitations, table 1,2 is only available as a download in the Supplemental Files section.

\section{Figures}




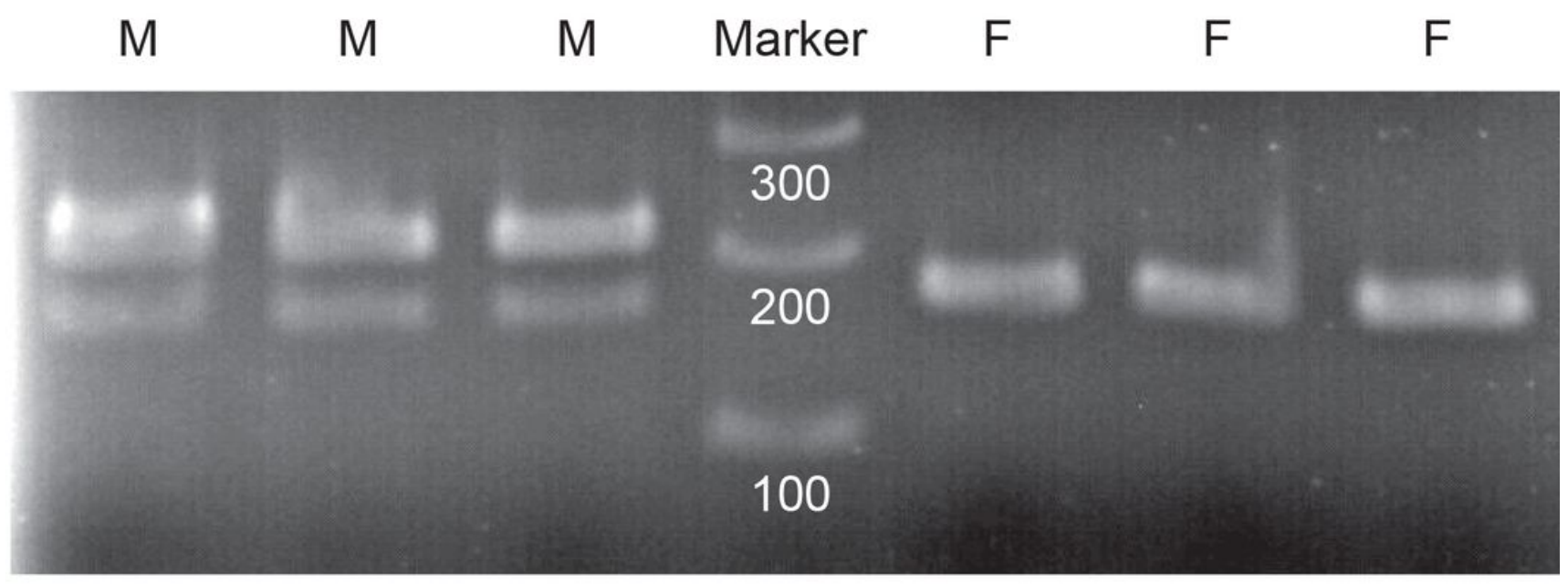

Fig. 1

\section{Figure 1}

The results using the sex identification markers for small Indian mongooses. $M$, male; $F$, female.

\section{Supplementary Files}

This is a list of supplementary files associated with this preprint. Click to download.

- Table1.xlsx

- Table2.pdf 